\title{
Early Warnings and Benefits Assessment for Disastrous Weathers during 2012 Typhoon Damrey
}

\author{
Yanjun Zhou Sha Wang
}

The Ocean Observatory of Qinhuangdao, Qinhuangdao Hebei 066000, China

\section{$2012^{\text {a16 }}$ 达维”台风灾害天气预警及效益评估}

\author{
周艳军王莎
}

河北秦皇岛海洋气象台, 秦皇岛, 066000

\begin{abstract}
The Typhoon Damrey, which was entering the Bohai Sea area of Qinghuangdao in 2012, is analyzed comprehensively and evaluated for services using the data from FY-2E Infrared, radar, Micaps 3.1 system, insular stations, buoys, and numerical products, and synchronously comparing between disasters report, early warning signals, guidance product from NMC, and in-situ service materials from Internet Meteorological Observatory. Results show: The Typhoon Damrey had a horizontal scale of $500 \mathrm{~km}$ when it's approaching Shandong Province, but reduced to $400 \mathrm{~km}$ when it's entering the west of Bohai Sea, with 9-11km height of cloud's top. Before 20:00, $3^{\text {rd }}$ August, indirect impacts were caused by the cloud system of typhoon, associated with precipitation from the peripheral of subtropical high. After 20:00, $3^{\text {rd }}$ August, the main body of Damrey's cloud system over the Bohai Seas, started taking effect. 28 villages and towns suffered rainfall over $200 \mathrm{~mm}$, with a maximum of $308 \mathrm{~mm}$. The average wind speed over sea is $19.3 \mathrm{~m} / \mathrm{s}$, with a maximum of $27.0 \mathrm{~m} / \mathrm{s}$. Areas with intense rainfall and strong wind located at the turning point of the subtropical high's ridge line with 5860 geopotential meters. The double effects from very low southeast jet over the sea are significant, which is both dynamic factor and short-time transportation of water vapor factor.
\end{abstract}

Our early warnings between 0-36 hours are accurate and timely.

Key words: Coastal Regions of the Bohai Sea, The Typhoon Damrey, Forecast and Early Warnings, Benefits Assessment

\section{摘要}

利用 FY-2E 红外云图、雷达、micaps3.1、 海岛站、浮标及数值产品检验资料, 同步对比 灾情报告、预警信号、中央台指导产品及“网 络气象台”现场服务资料等, 对 2012 年进入渤 海秦皇岛区域的“达维”台风进行综合分析及 服务评估。结果表明: 在山东一线的“达维”水 平尺度约 $500 \mathrm{~km}$, 进入渤海西部时约 $400 \mathrm{~km}$, 云顶高度 9-11km, 主要影响时段为: 8 月 3 日 20 时之前受台风云系间接影响, 以副热带高 压外围降水; 20 时之后受进入渤海的“达维” 主体系统云系影响, 28 个乡镇降水量超过 $200 \mathrm{~mm}$, 中心最大为 $308 \mathrm{~mm}$; 海上平均风速 为 $19.3 \mathrm{~m} / \mathrm{s}$, 最大风速为 $27.0 \mathrm{~m} / \mathrm{s}$; 强降水和大 风区位于副高“586 脊线”拐点处, 海区超低空 东南急流“双重效应”明显, 既是动力因子又是 水汽短时输送因子。0-36 小时预警准确及时。

关键词: 渤海海岸带, 达维台风, 预报预警, 效益评估

台风的破坏力主要由强风、暴雨和风暴潮 三个因素引起, 严重威胁沿海各省市的工农业 


\section{Risk Analysis and Crisis Response in Big Data Era (RAC-16)}

生产、交通运输和人民生命财产安全, 并被广 大气象工作者 ${ }^{[1]}$ 所关注。2012 年 8 月 3 日-4 日, 位于山东半岛北部 “达维” 台风北移及副 热带高压东退, 在渤海西部海区海岸带形成有 利强降水形势场和 NE-SW 向次天气尺度雨 带, 在渤海海区中尺度低层辐合风场、水汽因 子耦合下, 导致区域性重大灾害性天气的发 生。近年来, 科研部门曾开展过大规模的热带 气旋外场 ${ }^{[3]}$ 监测及数值模拟 ${ }^{[4.5]}$ 试验, 对台风

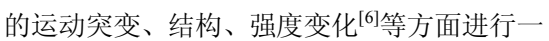
系列的研究, 一些科研成果应用在多次台风预 报中, 取得了较好的业务和社会效益。但对于 北上进入渤海一线的台风路径偏差 ${ }^{[7]}$ 及成因 ${ }^{[8]}$ 等仍处于探讨阶段; 尤其是 0509 号“麦莎”和 1109 号 “梅花”台风在渤海西部的预报、预警出 现较大误差。如何应用最新监测数据及本地预 报指标, 面对即将来临的“达维”台风做出科学 的判断? 结果表明: 这是近年来我台最成功的 一次台风大暴雨、海上大风预报，其中，应急 建立的“网上气象台”, 通过 VPN 访问方式, 实时向指挥部现场汇报雨情和精细化预报, 科 学展示了气象现代化在重大天气监测、预报能 力和水平, 在抗洪抢险关键时刻, 为省、市领 导防汛抗洪一系列科学决策赢得了宝贵时间。

\section{1. 实况与灾情概况}

\section{1 实况监测资料}

自 2012 年 7 月 21 日以来, 河北西海岸带 地区先后出现 5 次强降水天气过程, 平均降水 量大于 $400 \mathrm{~mm}$ 。“达维”造成的新一轮强降水天 气给抗洪抢险工作带来极大挑战, 8 月 3 日 08 时到 4 日 08 时, 秦皇岛、唐山 104 个乡镇降 水量超过 $100 \mathrm{~mm}$ (图 1), 有 40 个乡镇降水量 超过 $200 \mathrm{~mm}$, 小时最大降雨量为 $67 \mathrm{~mm}$, 中心 最大为秦皇岛海阳镇 $308 \mathrm{~mm}$, 雨量从西北至 东南向呈梯度分布, 沿海区域明显大于山区; 陆地最大风速达 $27.0 \mathrm{~m} / \mathrm{s}$, 海上平均风速 (图 2) 为 $19.3 \mathrm{~m} / \mathrm{s}$, 最大风速为 $25.3 \mathrm{~m} / \mathrm{s}(\mathrm{NE})$, 恰逢天文大潮, 沧州海岸带出现风暴潮灾害。

\section{2 灾情概况}

河北秦皇岛为此次天气过程的重灾区之 一, 3 座大型水库超过汛限水位、64 座中型水 库溢流, 冲毁乡镇级塘坝 104 个; 电力、通讯
设施及公里桥梁损毁严重; $90 \%$ 的沿海养殖户 “血本无归”; 位于南北铁路命脉的山海关火车 站因洪水导致路基边坡溜塌、编组站台被积水 包围 (图 3), 中断停运 24-36 小时。据市民政 部门统计: 因洪涝灾害共造成 174 万人受灾, 因灾死亡 3 人, 紧急转移安置 19 万人; 农作 物受灾面积 17 万公顷, 绝收 3 万公顷; 倒塌 房屋 1.6 万间, 直接经济损失达 194 亿人民币。 灾情加重与前期强降水重复叠加相关。

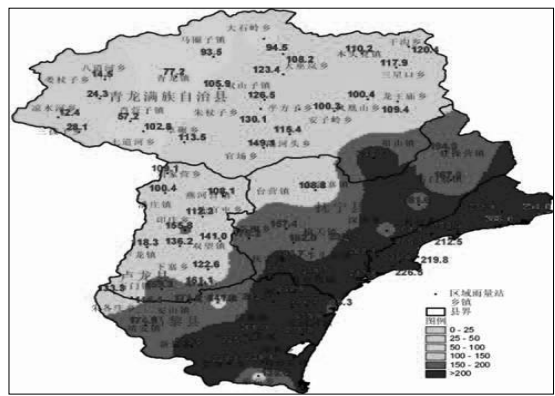

图 1：2012 年 8 月 3 日 08 时-4 日 08 时 (北京) 秦 皇岛降水量(单位: $\mathrm{mm}$ )

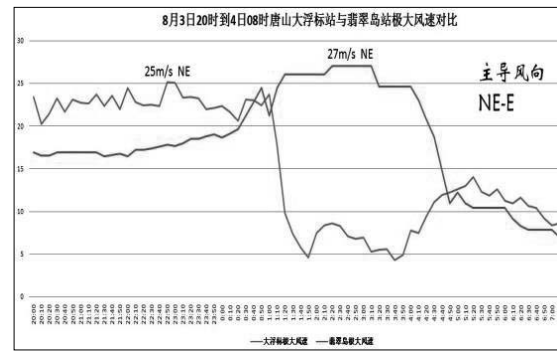

图 2: 2012 年 8 月 3 日 20 时-4 日 08 时（北京） 大浮标与海岛站风速(单位: $\mathrm{m} / \mathrm{s}$ )

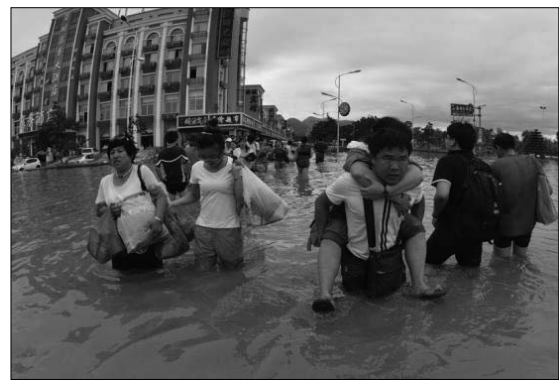

图 3: 2012 年 8 月 4 日 08 时 (北京) 山海关火车 站北侧广场 
Risk Analysis and Crisis Response in Big Data Era (RAC-16)

\section{2. 预报着眼点、难点及应用技术}

2.1 预报着眼点

近 8 年中, 秦皇岛台曾经有过 2 次台风 预报空报,一次消空预报: 即 2005 年“麦莎”、 2011 年“梅花”及“米雷”预报，目前的“达维” 同样出现了 0-72 小时 EC/T639 预报路径及 中央台、省台结论存在分歧情况，预报结论 不断被订正, 参考前 5 次暴雨落区形势场, 采用 FY-2E 红外云图与实况雨量叠加、雷达 拼图、海岛站等，实时对比 EC/T639、中央
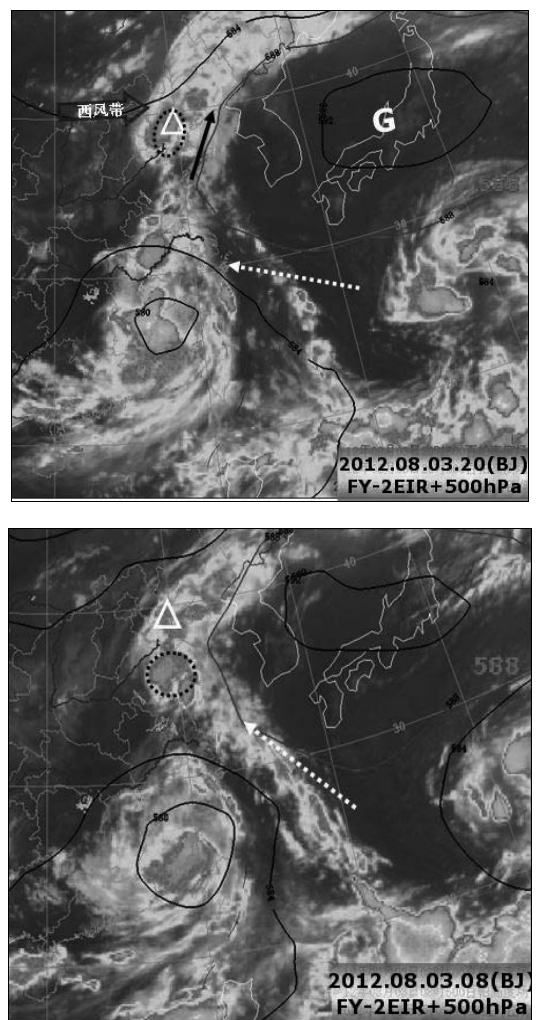

图 4: “达维” FY-2E 红外红外云图 12 小时对比及 $500 h p a$ 副高叠加分析图

台数值产品检验资料, 查阅进入黄渤海区域 的“麦莎”、“米雷”及“梅花”台风云图特征对 比分析结果 (图 4), 得出副高 586 脊线中心 在大连-黄海中部, 海区超低空东南风急流 动力因子与水汽短时输送因子“双重效应” 明显, 与 3 次台风相比路径偏西, 北上的“达 维”系统云系有利于河北海岸带强降水天气
的发生发展。其主要预报着眼点为: 副高 12-24 小时 586 线位置, $925 \mathrm{hpa}$ 水平风场特 征 (浴旋型有利于海岸带大暴雨); 卫星监 测水平尺度和雷达监测高度（大于 $9 \mathrm{~km}$ ); 1000-925hpa 存在明显低空东南风急流动力 因子; 进入 $38^{\circ} \mathrm{N}, 121^{\circ} \mathrm{E}$ 以西的中尺度低值 系统, 将会沿副高 586 线边缘快速北上, 超过 $39^{\circ} \mathrm{N}$ 时, 在西风带作用下移向转为东 北, 移速加快, 3-6h 后影响辽宁南部地区。

\section{2 预报难点}

72 小时路径不确定; 24 小时次天气尺度 达维浴旋状云系在进入渤海后加强的依据 不充分，单站大暴雨中心不好确定，把它视 为 “副高边缘中尺度浴旋类” 降水量小于 $180 \mathrm{~mm}, 14-20$ 时山东实况最大为 $104 \mathrm{~mm}$; “双 台风直接或间接效应” 对系统移速及强度变 化不确定, 事实上比 “副高边缘中尺度涡旋 类” 移动速度慢 6-8 小时。08 时达维受副高 588 线边缘带状云系 (SE引导气流) “汼制” 并从菲律宾东部海区热带云团中补充能量 (上图 4)；20 时副高西伸苏拉北部中尺度 云团发展构成径向超天气尺度云带, 但在西 风带和副高 SW 急流引导下, 加快 NE 向移速 脱离苏拉双台风效应的影响, 转为 “副高边 缘中尺度云团暴雨类型”。

2.3 预警情况

“达维” 台风起报时间为 8 月 2 日 11 时, 预报 3 日夜间-4 日上午影响河北海岸 带。由于中央台、河北省台预报会商意见不 一致, 初步意见为中-大雨, 局部暴雨; 随 资料更新, 结合近年来海岸带大暴雨天气概 念模型及 925 pa 急流、云模式因子、海洋 模式因子应用指标, 8 月 3 日 11 时逐步订正 为 24 小时暴雨转大暴雨, 海区东南风 8-9 级。

8 月 3 日 16 时中央台与河北台、秦皇岛 会商意见：强降水大于 $150 \mathrm{~mm}$ 、局部大于 $200 \mathrm{~mm}$ ，海区大风 8-9 级。

8 月 3 日 21 时中央台与河北台、秦皇岛 台加密会商意见：强降水大于 $200 \mathrm{~mm}$ 、局部 大于 $250 \mathrm{~mm}$, 海区大风 8-9 级、阵风 10 级。 秦皇岛气象台对外发布预报意见（表 1) 
Risk Analysis and Crisis Response in Big Data Era (RAC-16)

表 1： 2012 年 8 月 2 日- 4 日 “达维” 台风即将进入渤海西部海区对公众发布的预报

\begin{tabular}{ccccccc}
\hline 发布时间 & 24 小时 & 48 小时 & 72 小时 & 陆地风向风速 & 海 区 & 注 \\
\hline $0802 \backslash 11$ & 多云转阵雨 & 中雨转大雨 & 中雨转多云 & 东南 3-4 级 & 东南 5-6 级 & 3 条路径意见 \\
$0802 \backslash 17$ & 阵雨转大-暴雨 & 暴雨转中雨 & 小雨转多云 & 东南 4-5 级 & 东南 5-6 级 & 3 条路径意见 \\
$0803 \backslash 05$ & 大-暴雨转暴雨 & 中雨转小雨 & 多云 & 东南 4-5 级 & 东南 7-8 级 & 2 条路径意见 \\
$0803 \backslash 11$ & 暴雨转大暴雨 & 大雨转小雨 & 多云 & 东南 6-7 级 & 东南 8-9 级 & 2 条路径意见 \\
$0803 \backslash 17$ & 大暴雨转大雨 & 中雨转小雨 & 多云 & 东南 6-7 级 & 东南 8-9 级 1 条路径特大暴雨 \\
$0804 \backslash 05$ & 中雨转多云 & 多云 & 多云转晴 & 东北 5-6级 & 东北 7-8 级 & \\
\hline
\end{tabular}

2.4 基于 “达维” 的天气监测与预报应用技 术

如何克服失误个例的阴影, 面对即将来 临的 “达维” 台风能否做出科学的判断? 关 键技术来源于“三大系统”综合应用能力 (图 5 ), 在常规预报发布之后, 为使服务达到最 佳效果, 应用 “网络气象台” 最新数值产品、 指导预报及监测资料进行逐步订正是其重 要环节之一。实时调阅 $\mathrm{FY}-2 \mathrm{E}$ 红外云图与实 况雨量叠加、雷达拼图、海岛站等, 对比最 新台风路径预报、6 小时降水落区、逐小时 红外云顶 TBB 分布等资料, 进一步确定降水 峰值及结束时段, 与前 3 次台风相比预报的 路径偏西, 为预警信号升级提供依据。

\section{2 应急网络气象台的服务效益}

7 月 21 日-8 月 2 日, 秦皇岛地区平均 雨量大于 $400 \mathrm{~mm}$, 灾民逐步转移, 北戴河 “十 八大” 筹备会即将召开, 省、市决策层领导 在焦急等待最后结论......但是由于多种原 因, 省、市领导无法在秦皇岛市防汛办现场 调阅最新的气象资料, 仅能查阅秦皇岛市气 象台每隔 1-2 小时通过传真方式向市防汛办 发送的最新雨情和预报信息, 时效性、针对 性都大打折扣。根据服务需求, 省、市气象 局领导直接督办, 于 8 月 2 日夜间在秦皇岛 市防汛办建立了 “网上气象台”: 通过 VPN 访问方式, 把 MICAPS、卫星云图、天气雷达、 自动雨量站等预报资料实现网络共享, 其时

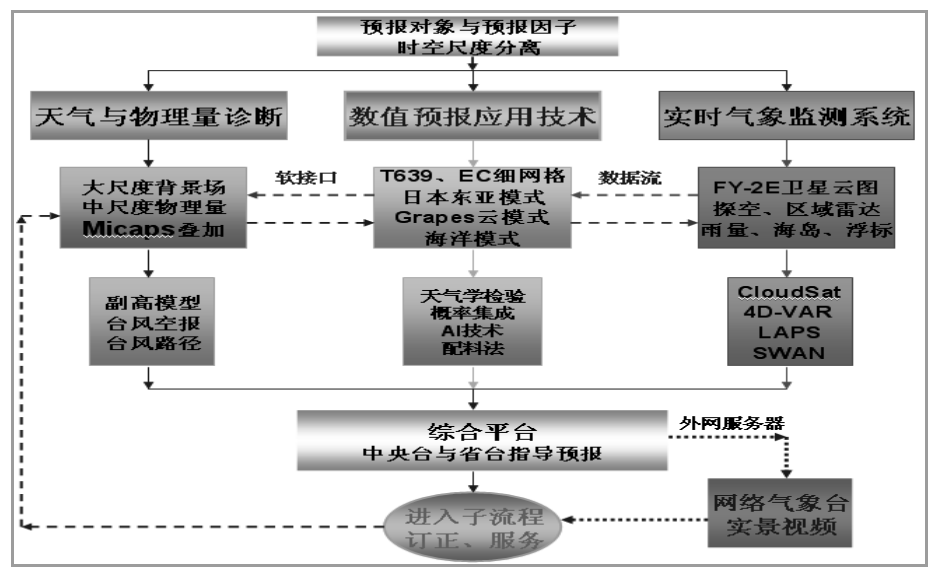

图 5: “达维” 台风预报应用技术业务流程

\section{3. 决策服务及效益评估}

3.1 重要天气报告与预警信号发布

在上述预报结论基础上, 按照业务流程 及监测服务规范, 逐步升级并及时解除预警 信号（见表 2)。
效性和真实的气象台一致。实时向指挥部汇 报雨情和短临预报, 科学展示了气象现代化 在重大天气监测、预报方面的能力和水平。 在抗洪抢险 “关键时刻”, 为省、市领导做 出一系列科学决策赢得了宝贵时间。 
Risk Analysis and Crisis Response in Big Data Era (RAC-16)

表 2: 2012 年 “达维” 台风进入渤海西部岸区决策服务与预警发布

\begin{tabular}{lllll}
\hline 内容 \时间 重要天气报告 & \multicolumn{2}{l}{ 预警信号 1} & 预警信号 2 & 应急响应与启动预案 \\
\hline $0802 \backslash 10$ & 重要天气报告 & 大雨 & 暴雨 & 起草市级III应急预案报告 \\
$0802 \backslash 16$ & 北戴河服务专报 & 大-暴雨 & 暴雨 & 发布图标 “中国气象局” \\
$0803 \backslash 07$ & 重要天气报告 & 大暴雨 (特大) & 海上大风 & 政府启动III应急预案、省政府 II 应急预案 \\
$0803 \backslash 08$ & 预警信号发布 & 台风黄色 & 暴雨黄色 & 24 小时河北秦皇岛电视滚动、全网短信 \\
$0803 \backslash 09$ & 北戴河服务专报 & 台风黄色 & 暴雨黄色 & 发布图标 “中国气象局” \\
$0803 \backslash 16$ & 继续预警信号发布 台风黄色 & 暴雨黄色 & 24 小时河北秦皇岛电视滚动、II 应急预案 \\
$0804 \backslash 02$ & 暴雨预警信号升级 台风黄色 & 暴雨红色 & 24 小时河北秦皇岛电视滚动、新闻专报 \\
$0804 \backslash 06$ & 解除暴雨预警信号 & & \\
$0804 \backslash 11$ & 解除台风预警信号 & & \\
\hline
\end{tabular}

3.2. 1 网络气象台临时成为省、市领导决策 中心

8 月 3 日下午 16 时,省领导来到秦皇岛 市防汛办指导工作，当得知强降水在 20 时 以后加大, 过程量级大于 $200 \mathrm{~mm}$ 时, 现场召 集市领导决定滦河分洪，爆破时间必须在 0 时之前, 大型水库泄洪由 2000 立方/秒加大 到 3000 立方/秒, 要求电视台及手机运营商 全网发布预警信息。

8 月 3 日晚 21 时省领导与预报员进行视 频会商, 根据最新的中央台、省台与秦皇岛 台加密会商结论, 决定加大卢龙、抚宁转移 群众力度, 人数增加到 10 万。

\section{2.2 后续效益}

8 月 21 日, 河北省政府召开表彰大会, 给河北省气象局 6 个先进单位名额, 5 个先 进个人; 同时秦皇岛市政府给市局 10 个先 进个人 (“奥运会” 仅给 2 人次)。

8 月 28 日, 省领导批示: “7 $\cdot 21$ ” 华 北特大暴雨和台风 “达维” 给河北造成了 较为严重的气象灾害, 气象部门预报准确、 预警及时, 使人员伤亡和和财产损失降到了 最低限度, 在防灾减灾和应急服务中发挥了 不可替代的重要作用。

9 月 17 日,世界气象组织主席戴维・格 莱姆斯在上海听取 “海葵” 台风的预报服 务情况之后，对台风预报服务中与政府部门 的 “有效互动” 表示高度赞赏, 并表示世界 气象组织将会把的经验推广到全球城市防 灾中去。

\section{4. 结论与探讨}

(1) 进入渤海秦皇岛区域的 “达维” 台 风降水过程分为两个时段: 8 月 3 日 20 时之 前受台风云系间接影响, 主要为副热带高压 外围降水, 20 时之后受进入渤海 “达维” 主 体系统云系影响, 副高 12-24 小时 586 线位 置, 925hpa 水平风场特征 (浴旋型有利于海 岸带大暴雨); 卫星监测水平尺度和雷达监 测高度 (大于 $9 \mathrm{~km}$ ); 1000-925hpa 存在明显 低空东南风急流动力因子; 进入 $38^{\circ}$ $\mathrm{N}, 121^{\circ} \mathrm{E}$ 以西的中尺度低值系统, 将会沿副 高 586 线边缘快速北上, 超过 $39^{\circ} \mathrm{N}$ 时, 在 西风带作用下移向转为东北, 移速加快, 强 降水和大风区位于副高 “586 脊线” 拐点处 (高空急流), 海区超低空东南急流 “双重 效应” 明显, 既是动力因子又是水汽短时输 送因子。

72 小时预报路径不确定： 24 小时预报 次天气尺度达维涡旋状云系在进入渤海后 加强的依据不充分, 把它视为 “副高边缘中 尺度涡旋类” 降水量小于 $150 \mathrm{~mm}, 14-20$ 时 山东实况最大为 $104 \mathrm{~mm}$, “双台风直接或间接 效应” 对系统移速及强度变化不确定, 事实 上比 “副高边缘中尺度浴旋类” 移动速度慢 6-8 小时, 08 时达维受副高 588 线边缘带状 云系 (SE 引导气流) “汼制” 并从菲律宾东 部海区热带云团中补充能量; 20 时副高西伸 苏拉北部中尺度云团发展构成径向超天气 尺度云带, 但在西风带和副高 SW 急流引导 下，加快 $\mathrm{NE}$ 向移速脱离苏拉双台风效应的 影响, 转为 “副高边缘中尺度云团暴雨类 
Risk Analysis and Crisis Response in Big Data Era (RAC-16)

型”。

（2）面对 “50 年一遇” 的强降水及大风 天气过程能否做出科学判断? 关键技术来 源于 “三大系统” 综合应用能力。与前 3 次 台风相比是路径最偏西的一次, 其中, 天气 概念模型应用; 总结渤海台风预报失误与成 功经验; 最新数值产品、指导预报及监测资 料的应用进一步确定降水峰值及结束时段, 为预警信号升级或解除提供依据。应急建立 的网络气象台为预报与决策服务进行无缝 隙连接提供了技术支撑。

(3) 认真汲取 “北京 7.21 ” 预报与服务 经验, 0-36 小时预警准确及时, 定位误差小 于 $100 \mathrm{~km}$; 在前期 5 次强降水天气过程成功 预报背景下, 增强了省、市领导对预报结论 的可信度, 使 “网络气象台” 现场服务效果 达到最佳, 为省市领导一系列科学决策争取 了宝贵的时间, 提前转移群众 19 万, 取得 了良好的社会效益, 为决策与应急服务方式 提供了新的思路。

（4）海上大风风向误差大于 50 度, 陆 地大于 120 度; 对城市内涝及海岸带养殖区 灾害天气的影响严重性估计不足, 对偏东风 持续时间、天文大潮对岸区增水作用研究甚 少, 致使各河道排水出口低于海平面, 排水 畅通时间后延 6-8 小时。海岸带-海区不同 行业灾害风险评估技术手段、能力和水平相 对落后, 亟待提高。

项目资助: 环渤海区域科技协同创新基金项目 (黄渤海雷暴大风监测及预警指标研究 QYXM201502）.

\section{参考文献}

[1]方宗义, 许健民, 赵风生.中国气象卫星和卫 星气象研究的回顾和发展; 气象学 报;2004,62(5):2-6.

[2]陈联寿. 热带气旋研究和业务预报技术的发 展.应用气象学报,2006,17(6): 672-676.

[3] 张光智,徐祥德.采用外场观测试验资料对登 陆台风"黄蜂"的风场及湍流特征的观测研 究.应用气象学报,2004 年 01 期

[4] 毕宝贵, 林建, 徐晶.气象卫星资料在天气预 报分析业务中的应用.气象, $2004 \mathrm{Vol} .30$
No.11 P.19-23

[5]李燕,黄振.对"麦莎"路径及造成黄渤海域大 风浪的数值模拟.气象科技 2007 Vol.35 No.2 P.175-179.

[6]刘学刚,李庆宝,张金艳.近年来引发青岛暴 雨的台风特征分析. 气 象,2011,37(9):1091-1099.

[7]刘健, 张文建, 朱元竞等.中尺度强暴雨云团 云特征的多种卫星资料综合分析.应用气象 学报, 2007 Vol.18 No.2 P.158-164.

[8]何立富, 尹洁,陈涛,罗金秀.0509 号台风麦莎 的结构与外围暴雨分布特征.气 象,2006,32(3):93-100.

[9]Guo Shujun, The Meteorological Disaster Risk Assessment Based on the Diffusion Mechanism. Journal of Risk Analysis and Crisis Response, Vol. 2, No. 2 (August 2012), 124-130

[10]Wang wei, Zhou chao, Du xin. The Research of a Hail Risk Evaluation under Imperfect Information. Journal of Risk Analysis and Crisis Response, Vol. 1, No. 2 (November 2011), 133-141 